\title{
A boy with recurrent pneumonia
}

E. Mantzouranis

K. Mathianaki

M.D. Fitrolaki

E. Mihailidou

P. Paspalaki

A 6-yrold boy was admitted to the paediatric department of the University of Heraklion (Heraklion, Greece) with fever $\left(38.5^{\circ} \mathrm{C}\right)$, respiratory distress and had been coughing for 2 days. He was well prior to admission.

His past medical history was remarkable for frequent episodes of bronchiolitis and bronchitis from age 7 months until 3 yrs, followed by one episode of bronchitis per year, thereafter. In the second day of life, he was hospitalised for tachypnoea, attributed to laryngomalacia. He was full-term, born by caesarean section, due to decreased heart sounds. His neonatal history was negative. He is the oldest of four healthy siblings. His family history is negative.

On physical examination, the boy was slightly pale, had tachypnoea and respiratory distress. He was well-developed and nourished. His temperature was $37^{\circ} \mathrm{C}$, respiratory rate was 28 breaths $\cdot \mathrm{min}^{-1}$, pulse was 117 beats $\cdot \mathrm{min}^{-1}$ and $\mathrm{O}_{2}$ saturation was $87 \%$. Chest auscultation revealed decreased breath sounds and crackles over the right lower hemi-thorax. His cardiac sounds $S_{1}$ and $S_{2}$ were normal. His throat was slightly congested. The rest of his physical examination was normal.

His chest radiography (CXR) is shown in fig. 1.

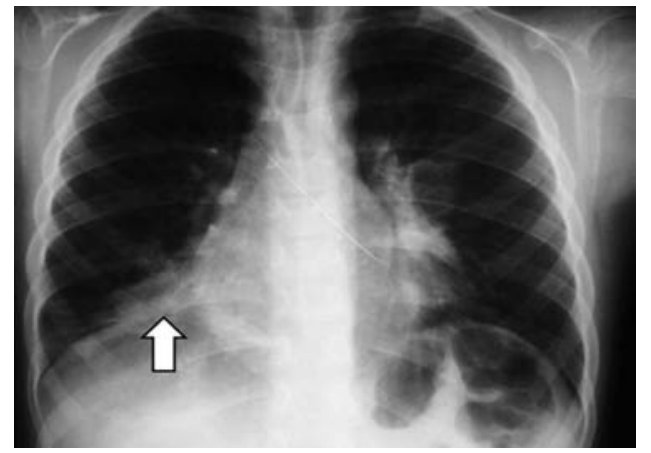

Figure 1

Chest radiograph

Task 1

How would you interpret the CXR?
Division of Pulmonary, Allergy and Immunology, Dept of Pediatrics,

University Hospital of Heraklion, University of Crete, Heraklion,

Crete,

Greece

\section{Correspondence}

E. Mantzouranis

Associate Professor of Pediatrics University of Crete

Director of the Division of

Pulmonary Allergy and

Immunology

Dept of Pediatrics

University Hospital of Heraklion

Heraklion, 71110

Crete

Greece

mantzourani@med.uoc.gr

\section{Competing interests}

None declared. 


\section{Answer 1}

The anterio-posterior (AP) CXR showed right lower lobe opacity (arrow), a small shift of the mediastinum to the right and blurring of the left lower cardiac border.

Blood test results are shown in table 1. Blood chemistry tests were normal. Blood cultures and antibodies to mycoplasma were ordered.

\section{Table 1. Blood test results}

\begin{tabular}{|c|c|}
\hline $\mathrm{pH}$ & 7.36 \\
\hline \multicolumn{2}{|l|}{ Arterial blood gases } \\
\hline $\mathrm{SO}_{2} \%$ & 91 \\
\hline $\mathrm{PCO}_{2} \%$ & 40 \\
\hline $\mathrm{PO}_{2} \%$ & 62 \\
\hline $\mathrm{HCO}_{3} \%$ & 22 \\
\hline Actual base excess & -3 \\
\hline White blood cells cells $\mathrm{mm}^{-3}$ & 18,700 \\
\hline Polymorphonucleates \% & 79.4 \\
\hline Lymphocytes \% & 14.5 \\
\hline Monocytes \% & 4.9 \\
\hline Eosinophils \% & 0.7 \\
\hline Haemoglobin $\mathrm{g} \cdot \mathrm{L}^{-1}$ & 12.7 \\
\hline Haematocrit \% & 36.4 \\
\hline Platelets $\mathrm{n} \cdot \mathrm{mm}^{-3}$ & 309,000 \\
\hline $\begin{array}{l}\text { Erythrocyte sedimentation rate } \\
\mathrm{mm} \cdot \mathrm{h}^{-1}\end{array}$ & 41 \\
\hline C-reactive protein $\mathrm{mg} \cdot \mathrm{dl}^{-1}$ & 27 \\
\hline
\end{tabular}

\section{Task 2}

What is your possible diagnosis? 


\section{Answer 2}

Based on the clinical picture, CXR findings, increased leukocytes, neutrophils, erythrocyte sedimentation rate and C-reactive protein, the diagnosis of pneumonia of right lower lobe was made.

The patient was treated with intravenous penicillin. Due to episodes of bronchitis, methylprednisolone $\left(1 \mathrm{mg} \cdot \mathrm{kg}^{-1} \cdot \mathrm{day}^{-1}\right)$ and inhaled salbutamol were also administered. On the second day of admission, fever persisted and oral clarithromycin was added. The fever subsided the fourth day. On the following day, CXR was repeated (fig. 2).

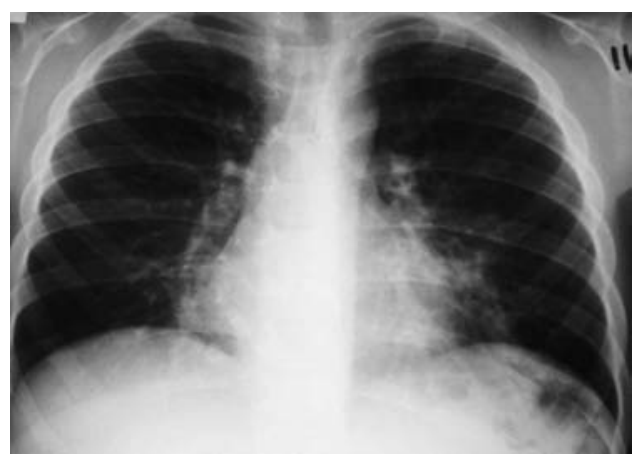

Figure 2

Task 3

How would you read the second CXR? 


\section{Answer 3}

CXR showed partial resolution of the opacity, no signs of mediastinal shift, small infiltrate on the right mid-lower lobe and blurring of the left lower cardiac boarder.

The patient received the aforementioned treatment for 8 days. Repeated blood test results are shown in table 2.

\section{Table 2. Repeated blood test}

$\begin{array}{ll}\text { White blood cells cells } \cdot \mathbf{m m}^{-3} & 14,100 \\ \text { Polymorphonucleates \% } & 72.6 \\ \text { Lymphocytes \% } & 19.3 \\ \text { Monocytes \% } & 4.3 \\ \text { Eosinophils \% } & 3.1 \\ \text { Haemoglobin } \mathbf{~} \cdot \mathbf{L}^{-1} & 12.4 \\ \text { Haematocrit \% } & 37.4 \\ \text { Platelets } \mathbf{n} \cdot \mathbf{m m}^{-3} & 418,000 \\ \text { Erythrocyte sedimentation rate } & 28 \\ \text { mm } \mathbf{h}^{-1} & \\ \text { C-reactive protein } \mathbf{m g} \cdot \mathrm{dl}^{-1} & 0.42\end{array}$

Chemistry tests were normal. Blood cultures (twice) showed no growth. Cold agglutinins and pneumococcus antigen in the urine were negative. Immunoglobulin $(\mathrm{Ig}) \mathrm{G}$ and $\mathrm{IgM}$ antibodies to Mycoplasma, Chlamydia and Rickettsiae spp., were pending.

He was discharged on the 8th day, advised to continue clarithromycin for 4 days, salbutamol for 6 days, methylprednisolone $(4 \mathrm{mg})$ for 2 days and to return for assessment in 10 days. At his follow-up appointment, he was well and was advised to return to normal life.

12 months later, the patient was re-admitted with fever $\left(38.5^{\circ} \mathrm{C}\right)$, dyspnoea and cough for 2 days. He appeared ill...

To be continued next issue... 